\title{
ENTREVISTA
}

\section{Literatura y ámbito masónico. A propósito de la novela Pequeñeces, del jesuita Luis Coloma}

El escritor e investigador Ricardo Serna Galindo ha defendido una tesis doctoral cuyo título es "Literatura y ámbito masónico. A propósito de la novela Pequeñeces, del jesuita Luis Coloma”. El acto de presentación y defensa de esta tesis tuvo lugar en la sala de grados del edificio Zabaleta, de la Universidad de Jaén (España), el 5 de julio de 2017. Dirigió la tesis el profesor titular y catedrático acreditado Dr. Juan Manuel Matés Barco ${ }^{1}$.

El autor nació en Zaragoza, España en octubre de 1954. Y nos ha concedido la siguiente entrevista.

¿Cuáles fueron los motivos que le llevaron a enfocar su investigación hacia la masonería?

En principio, el tema de la masonería me ha resultado atractivo siempre. El primer contacto que tuve con el asunto data de mi etapa de estudiante universitario, y desde esas fechas ha llovido bastante. A partir de 1996, siendo ya miembro de Centro de Estudios Históricos de la Masonería Española (CEHME), aumentaron mis trabajos sobre la relación existente entre lo literario y lo masónico, llegando a especializarme en ese campo con más intensidad. Pero el punto de partida de esta investigación, que ahora culmina con la defensa de la tesis doctoral, hay que situarlo en 1998. En esa fecha, la Fundación Universitaria Española de Madrid tuvo a bien publicar mi libro Masonería y Literatura. La Masonería en la novela emblemática de Luis Coloma. A partir de la edición de este libro, me propuse ir ahondando en este mismo tema, a la vez que iba publicando algunos artículos y ensayos en revistas diversas. Una vez que fui consciente de que tenía material suficiente para la realización de una tesis doctoral, me puse a ello con dedicación plena a mediados de 2014.

¿Cuáles han sido las fuentes que ha utilizado?

Principalmente fuentes bibliográficas, porque aunque la tesis es un trabajo de un historiador, llevado a cabo además a través del método historiográfico, la investigación se basa en el análisis del fondo y forma de una obra literaria, la novela Pequeñeces del padre Coloma, un novelista español del siglo XIX que, desde mi punto de vista, es una de las cinco mejores plumas de la centuria. Es evidente que aparte de las fuentes bibliográficas, he

\footnotetext{
${ }^{1}$ Más información en el sitio: https://ricardo-serna.blogspot.com.es/2017/07/tesis-doctoral.html
} 
recurrido a fuentes de archivos, entre ellos a los de la Universidad Pontificia de Comillas y el del Centro Documental de la Memoria Histórica de Salamanca.

¿Con qué dificultades principales se ha encontrado en el camino, y cómo las ha superado?

Aunque parezca una contradicción, la falta de literatura crítica en torno al asunto de mi investigación, me ha obligado a centrarme mucho más en la revisión pormenorizada de la biografía de Luis Coloma y a relacionar luego su vida personal con los argumentos masónicos que aparecen en Pequeñeces, una novela llena de claves y misterios que poca gente conoce bien. También me ha llevado mucho tiempo la organización del material y la propia redacción formal de la tesis, que he procurado cuidar al máximo.

¿Quiere destacar algún aspecto que no se haya contemplado en esta entrevista y que considere digno de reseñar?

Se podría decir mucho más de esta Tesis, claro está, sobre todo de las numerosas conclusiones que enriquecen sin duda la visión que hoy se tiene del Coloma narrador, un autor al que es preciso reivindicar con decisión y estudiar sin complejos en profundidad. $\mathrm{Su}$ novela Pequeñeces nos ofrece un testimonio histórico, tamizado por la subjetividad del factor literario, de la segunda mitad del siglo XIX en España. No solo constituye una fuente válida para los historiadores de la época, sino que forma parte de esa novelística impagable que ofrece un relato distinto y original de los hechos vividos por el escritor. Un testimonio de lo acontecido, de lo experimentado, que late en el fondo de los argumentos de la novela.

Sí me gustaría destacar -y así lo hice también ante el tribunal que juzgó mi trabajoque esta Tesis tiene un plus de novedosa originalidad en lo que respecta al análisis mismo de la novela, puesto que no responde en absoluto a las visiones históricas ni filológicas con que se ha venido estudiando Pequeñeces hasta el momento, sino que la perspectiva nace de los oteros de la masonología, un punto de vista inédito hasta la fecha para el análisis de la obra de Coloma.

También me gustaría añadir que estoy muy satisfecho del resultado académico de mi trabajo, calificado de «Sobresaliente cum laude», y que es mi gusto y obligación agradecer una vez más la muy valiosa ayuda de mi director de tesis, el profesor Matés, de la Universidad de Jaén, así como los incentivos útiles del profesor Ferrer Benimeli, de mi esposa Laura y de todos esos amigos y colegas que estuvieron pendientes de alguna forma de la evolución y desarrollo de mi labor durante estos últimos años. Mi gratitud a todos.

Esta entrevista se efectúo de forma telemática el 1 de agosto de 2017.

Autores de la entrevista: Ricardo Martínez Esquivel e Yván Pozuelo Andrés, director y editor de REHMLAC+, doi: https://doi.org/10.15517/rehmlac.v9i2.30053 